See Article page XXX.

\section{Commentary: Complete revascularization in coronary artery bypass grafting - sometimes it pays to be conservative}

Thin X. Vo, MD, MSc, David Glineur, MD, PhD, and Marc Ruel, MD, MPH

In this issue of The Journal, Bianco and colleagues ${ }^{1}$ provide us with timely and provocative data on incomplete revascularization in coronary artery bypass grafting (CABG). While there is consensus that complete revascularization (CR) should be a key objective in CABG, how a surgeon achieves CR remains debatable. Some studies have demonstrated benefit, ${ }^{2}$ but CR has not consistently been correlated with improvement in long-term outcomes, ${ }^{3,4}$ probably due to heterogeneity in its definition. Previous definitions of CR have included anatomical, territorial, functional, completeness of revascularization index, as well as the residual SYNTAX score. ${ }^{3-5}$

Keeping in mind the limitations of retrospective analyses, Bianco and colleagues provide evidence for a correlation between CR and a lower incidence of major adverse cardiac and cerebrovascular events (MACCE) at median follow-up of 3.6 years. The validity of their findings is enhanced using inverse proportional treatment weighting to balance the comparison groups.

The authors' main analysis used a largely anatomicbased definition, in which grafting of all stenotic vessels was considered CR. Their secondary analysis used a more conservative, territory-based approach where grafting of all affected "main-branch" vessels was considered CR.

\footnotetext{
From the Division of Cardiac Surgery, University of Ottawa Heart Institute, Ottawa, Ontario, Canada.

Disclosures: The authors reported no conflicts of interest.

The Journal policy requires editors and reviewers to disclose conflicts of interest and to decline handling or reviewing manuscripts for which they may have a conflict of interest. The editors and reviewers of this article have no conflicts of interest.

Received for publication June 30, 2021; revisions received June 30, 2021; accepted for publication July 1, 2021

Address for reprints: Marc Ruel, MD, MPH, Division of Cardiac Surgery, University of Ottawa Heart Institute, 40 Ruskin St, Ottawa, Ontario, Canada K1Y4W7 (E-mail: MRuel@OttawaHeart.ca).

J Thorac Cardiovasc Surg 2021; $\mathbf{\square}: 1-2$

$0022-5223 / \$ 36.00$

Copyright (C) 2021 by The American Association for Thoracic Surgery

https://doi.org/10.1016/j.jtcvs.2021.07.001
}

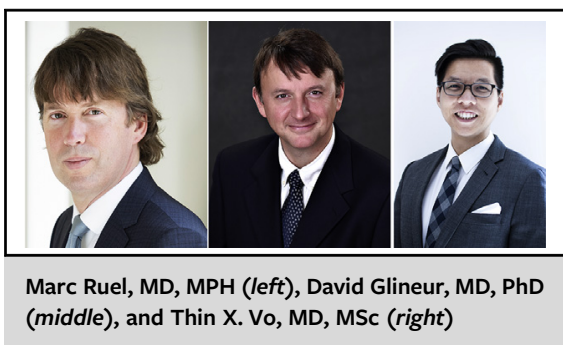

CENTRAL MESSAGE

Patients who receive complete revascularization do better than patients who do not. Whether these outcomes are due to the completeness of revascularization remains unproven.

Both analyses found statistically significant correlations between $\mathrm{CR}$ and a reduction in MACCE.

Interestingly, incomplete revascularization of nonmainbranch vessels such as an acute marginal, diagonal, or obtuse marginal did not adversely correlate with MACCE. This suggests that there may be a confounding effect that was not accounted for in the inverse proportional treatment weighting analyses or, somewhat provokingly, that nonmain-branch vessels may not necessarily require grafting.

We should not forget the fact that incomplete revascularization itself is a surrogate for severity of disease and patient comorbidities that may have made achieving CR less attractive in any given patient. No surgeon starts a CABG operation on an otherwise-healthy 60-year-old patient thinking "I'll incompletely revascularize today." Therefore, it is important to realize that it is the patients who receive CR, according to their clinical status or for other reasons, who do better long-term. Whether CR is the mechanism responsible for these outcomes remains uncertain, given the lack of prospective randomized data. Nonetheless, such data on this matter would be challenging to obtain.

Notably, the study by Bianco and colleagues did not have angiographic or imaging data, which would have helped correlate cardiac events with native disease progression versus graft failure. The reasons why patients were incompletely revascularized also are not known, although one can assume that those patients likely had worse coronary disease or comorbid burden. We also do not have information on the number of grafts performed per patient or per territory, which would have provided more detail regarding the revascularization strategies adopted by the surgeons. 
Finally, more stringent definitions of "important" or "dominant" vessels would provide further clarity on target myocardial perfusion and ischemic burden. For instance, the amount of myocardium supplied by obtuse marginals and diagonals may vary depending on anatomy, vessel diameter, and vessel length, and revascularization of "important" vessels may improve long-term survival. ${ }^{6}$

Altogether, Bianco and colleagues suggest, based on their key finding that incomplete revascularization of nonmainbranch vessels did not correlate with MACCE, that a territorial-based definition (ie, main-branch revascularization) of CR may be sufficient to prevent MACCE, and that grafting of nonmain-branch vessels might be superfluous.

What about other considerations? Functional-guided revascularization via fractional flow reserve has not demonstrated convincing advantages and is not yet ready for primetime. ${ }^{7}$ There is also a body of evidence suggesting that multiple arterial grafting may limit the adverse outcomes observed with incomplete revascularization. ${ }^{8,9}$ Could it be that a simple strategy of multiple arterial grafts with 1 graft per territory be enough for most patients?

We thank Bianco and colleagues for sharing their important findings and hope to see further research in this field, so that we can develop a more unified approach to defining and guiding $\mathrm{CR}$ in $\mathrm{CABG}$.

\section{References}

1. Bianco V, Kilic A, Aranda-Michel E, Serna-Gallegos D, Ferdinand F, DunnLewis $\mathrm{C}$, et al. Complete revascularization during coronary artery bypass grafting is associated with reduced major adverse events. J Thorac Cardiovasc Surg. June 9, 2021 [Epub ahead of print].

2. Garcia S, Sandoval Y, Roukoz H, Adabag S, Canoniero M, Yannopoulos D, et al. Outcomes after complete versus incomplete revascularization of patients with multivessel coronary artery disease: a meta-analysis of 89,883 patients enrolled in randomized clinical trials and observational studies. J Am Coll Cardiol. 2013; 62:1421-31.

3. Leviner DB, Torregrossa G, Puskas JD. Incomplete revascularization: what the surgeon needs to know. Ann Cardiothorac Surg. 2018;7:463-9.

4. Vander Salm TJ, Kip KE, Jones RH, Schaff HV, Shemin RJ, Aldea GS, et al. What constitutes optimal surgical revascularization? Answers from the bypass angioplasty revascularization investigation (BARI). J Am Coll Cardiol. 2002;39: 565-72.

5. Melina G, Angeloni E, Refice S, Benegiamo C, Lechiancole A, Matteucci M, et al. Residual SYNTAX score following coronary artery bypass grafting. Eur J Cardiothorac Surg. 2017;51:547-53.

6. Bakaeen FG, Ravichandren K, Blackstone EH, Houghtaling PL, Soltesz EG, Johnston DR, et al. Coronary artery target selection and survival after bilateral internal thoracic artery grafting. J Am Coll Cardiol. 2020;75:258-68.

7. Spadaccio C, Glineur D, Barbato E, Di Franco A, Oldroyd KG, Biondi-Zoccai G, et al. Fractional flow reserve-based coronary artery bypass surgery: current evidence and future directions. JACC Cardiovasc Interv. 2020;13:1086-96.

8. Kieser TM, Curran HJ, Rose MS, Norris CM, Graham MM. Arterial grafts balance survival between incomplete and complete revascularization: a series of 1000 consecutive coronary artery bypass graft patients with $98 \%$ arterial grafts. $J$ Thorac Cardiovasc Surg. 2014;147:75-84.

9. Rosenblum JM, Binongo J, Wei J, Liu Y, Leshnower BG, Chen EP, et al. Priorities in coronary artery bypass grafting: is midterm survival more dependent on completeness of revascularization or multiple arterial grafts? J Thorac Cardiovasc Surg. 2021;161:2070-8.e6. 